\title{
Chemical and structural investigation of the role of both Mn and Mn oxide in the formation of manganese silicate barrier layers on $\mathrm{SiO}_{2}$
}

Cite as: J. Appl. Phys. 110, 054507 (2011); https://doi.org/10.1063/1.3630123

Submitted: 14 June 2011 . Accepted: 25 July 2011 . Published Online: 07 September 2011

P. Casey, J. Bogan, J. G. Lozano, P. D. Nellist, G. Hughes, et al.

ARTICLES YOU MAY BE INTERESTED IN

Synchrotron radiation photoemission study of in situ manganese silicate formation on for barrier layer applications

Applied Physics Letters 98, 113508 (2011); https://doi.org/10.1063/1.3567926

Chemical and structural investigations of the interactions of $\mathrm{Cu}$ with $\mathrm{MnSiO}_{3}$ diffusion barrier layers

Journal of Applied Physics 112, 064507 (2012); https://doi.org/10.1063/1.4752874

Self-forming diffusion barrier layer in Cu-Mn alloy metallization

Applied Physics Letters 87, 041911 (2005); https://doi.org/10.1063/1.1993759

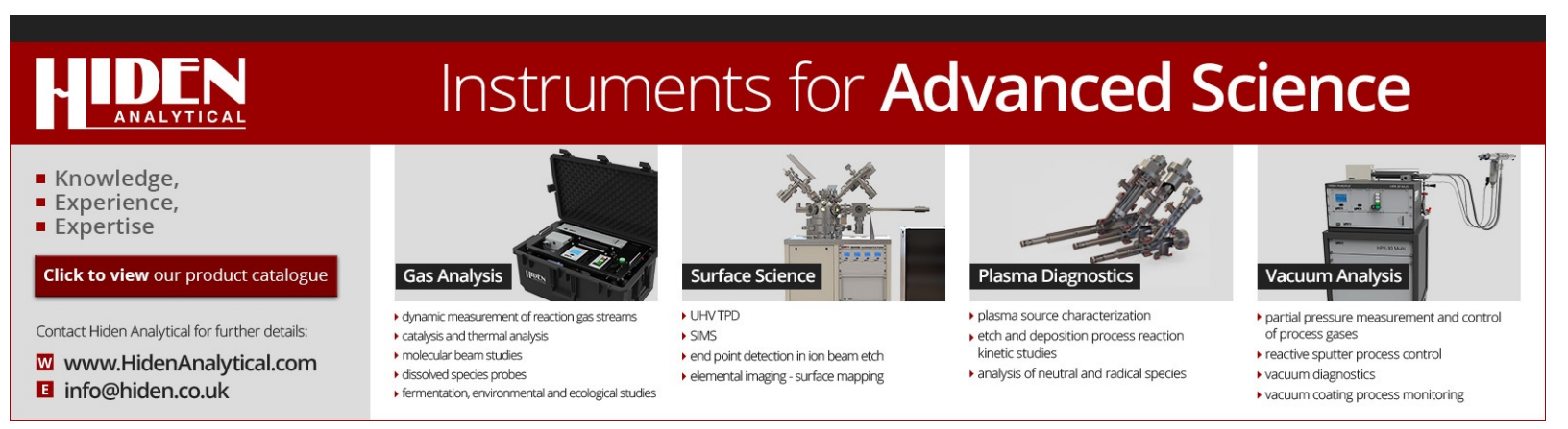




\title{
Chemical and structural investigation of the role of both Mn and Mn oxide in the formation of manganese silicate barrier layers on $\mathrm{SiO}_{2}$
}

\author{
P. Casey, ${ }^{1, a)}$ J. Bogan, ${ }^{1}$ J. G. Lozano, ${ }^{2}$ P. D. Nellist, ${ }^{2}$ and G. Hughes ${ }^{1}$ \\ ${ }^{1}$ School of Physical Sciences, Dublin City University, Glasnevin, Dublin 9, Ireland \\ ${ }^{2}$ Department of Materials, University of Oxford, Parks Road, Oxford OXI 3PH, United Kingdom
}

(Received 14 June 2011; accepted 25 July 2011; published online 7 September 2011)

\begin{abstract}
In this study, $\mathrm{Mn}$ silicate $\left(\mathrm{MnSiO}_{3}\right)$ barrier layers were formed on thermally grown $\mathrm{SiO}_{2}$ using both metallic $\mathrm{Mn}$ and oxidized Mn films, in order to investigate the role of oxygen in determining the extent of the interaction between the deposited $\mathrm{Mn}$ and the $\mathrm{SiO}_{2}$ substrate. Using x-ray photoelectron spectroscopy, it has been shown that a metallic Mn film with an approximate thickness of $1 \mathrm{~nm}$ cannot be fully converted to $\mathrm{Mn}$ silicate following vacuum annealing to $500^{\circ} \mathrm{C}$. Transmission electron microscopy (TEM) analysis suggests the maximum $\mathrm{MnSiO}_{3}$ layer thickness obtainable using metallic $\mathrm{Mn}$ is $\sim 1.7 \mathrm{~nm}$. In contrast, a $\sim 1 \mathrm{~nm}$ partially oxidized $\mathrm{Mn}$ film can be fully converted to Mn silicate following thermal annealing to $400{ }^{\circ} \mathrm{C}$, forming a $\mathrm{MnSiO}_{3}$ layer with a measured thickness of $2.6 \mathrm{~nm}$. TEM analysis also clearly shows that $\mathrm{MnSiO}_{3}$ growth results in a corresponding reduction in the $\mathrm{SiO}_{2}$ layer thickness. It has also been shown that a fully oxidized Mn oxide thin film can be converted to $\mathrm{Mn}$ silicate, in the absence of metallic Mn. Based on these results it is suggested that the presence of $\mathrm{Mn}$ oxide species at the $\mathrm{Mn} / \mathrm{SiO}_{2}$ interface facilitates the conversion of $\mathrm{SiO}_{2}$ to $\mathrm{MnSiO}_{3}$, in agreement with previously published studies. (C) 2011 American Institute of Physics. [doi:10.1063/1.3630123]
\end{abstract}

\section{INTRODUCTION}

Copper has now replaced aluminum as the metal of choice for interconnects in microelectronic devices, due to its lower resistivity and increased resistance to electomigration. ${ }^{1,2}$ However, studies have shown that a physical barrier is required to surround the $\mathrm{Cu}$ interconnect and prevent both the diffusion of $\mathrm{Cu}$ into the insulating $\mathrm{SiO}_{2}$ based dielectric materials, and the diffusion of $\mathrm{O}$ and $\mathrm{H}_{2} \mathrm{O}$ into the $\mathrm{Cu} .{ }^{3}$ Self forming diffusion barrier layers have been proposed as a scalable alternative to $\mathrm{Ta} / \mathrm{TaN}$ barrier layers for future interconnect generations. ${ }^{2}$ Both manganese silicate and manganese oxide barrier layers have been the subject of considerable study due to favorable alloying properties ${ }^{4}$ and improved copper adhesion compared to other barrier layer candidates such as TaN. ${ }^{1}$ In a recent high resolution photoemission study, Casey et al. ${ }^{5}$ have shown that $\mathrm{Mn}$ silicate $\left(\mathrm{MnSiO}_{3}\right)$ layers, free from $\mathrm{Mn}$ oxide, can be formed through ultra high vacuum (UHV) annealing of metallic $\mathrm{Mn}$ on thermally grown $\mathrm{SiO}_{2}$ surfaces. However, it was also shown that this Mn silicate growth method is self limiting at high temperature, with the maximum thickness of the $\mathrm{MnSiO}_{3}$ layer calculated to be approximately $2 \mathrm{~nm}$, resulting in the presence of residual metallic Mn on the surface following annealing. Previous studies ${ }^{6}$ have shown that unreacted metallic $\mathrm{Mn}$ remaining after barrier layer formation can diffuse to the surface of the deposited $\mathrm{Cu}$ interconnect during high temperature annealing and can be subsequently removed using an oxidation process. However, it has also been suggested that the presence of $\mathrm{Mn}$ within $\mathrm{Cu}$ during thermal annealing restricts $\mathrm{Cu}$ grain growth, leading to

\footnotetext{
a) Author to whom correspondence should be addressed. Electronic mail: patrick.casey8@mail.dcu.ie.
}

an increase in the final resistance of the interconnect. ${ }^{1,6}$ Therefore, it would be preferable if the Mn silicate growth reaction could be controlled more accurately in order to determine the thickness of the $\mathrm{MnSiO}_{3}$ layer and prevent the presence of residual metallic Mn.

Ablett et $a .^{7}$ have previously discussed the factors which determine the initial stages of Mn silicate growth on silica based dielectrics. It was suggested that absorbed water on dielectric surfaces leads to the presence of -OH groups, which interact with deposited Mn to form Mn oxide, with these $\mathrm{Mn}$ oxide species in turn reacting with silicon in the $\mathrm{SiO}_{2}$ to form $\mathrm{MnSiO}_{3}$. It has also been suggested that the absence of absorbed water species on thermally grown $\mathrm{SiO}_{2}$ layers reduces $\mathrm{Mn}$ oxide formation, hence limiting the maximum thickness of Mn silicate layers which can be formed on the surface. However, the precise role of $\mathrm{SiO}_{2}$, metallic $\mathrm{Mn}$ and Mn oxide species within the Mn silicate formation process has not been investigated experimentally. Therefore, the focus of this study is to determine if the thickness of $\mathrm{MnSiO}_{3}$ barrier layers grown on thermally grown $\mathrm{SiO}_{2}$ surfaces is limited by the presence of additional oxygen species, beyond that found within the $\mathrm{SiO}_{2}$ layer.

The chemical interactions between metallic Mn, partially oxidized Mn and fully oxidized Mn thin films on thermally grown $\mathrm{SiO}_{2}$ were systematically investigated using in situ X-ray photoelectron spectroscopy (XPS). The formation of Mn oxide species on the surface of dielectric materials through the presence of surface - $\mathrm{OH}$ groups, as described by Ablett et al., ${ }^{7}$ would be very difficult to control experimentally. Therefore, the experimental approach adopted in this study was to form partially oxidized and fully oxidized Mn thin films in UHV conditions through the evaporation of metallic $\mathrm{Mn}$ in a controlled oxygen background pressure. Also, 
given that barrier layer formation and XPS analysis was performed fully in situ in the UHV analysis system, this allowed the role of both oxidized and metallic species to be investigated without the complicating influence of ambient oxidation effects. Following the completion of XPS analysis, a protective copper capping layer (20-30 nm) was deposited on selected samples before they were removed from vacuum and subsequently analyzed by transmission electron microscopy (TEM), in order to accurately determine the thickness and uniformity of the $\mathrm{MnSiO}_{3}$ layers.

\section{EXPERIMENTAL DETAILS}

High quality thermally grown $\mathrm{SiO}_{2}$ layers on silicon, with a thickness of $5.4 \mathrm{~nm}$, were grown using the Semitool dry oxidation process in a Thermoco 9002 series furnace at $850^{\circ} \mathrm{C}$. The thickness of the thermal oxide was chosen so that the $\mathrm{Si}$ substrate $\left(\mathrm{Si}^{\circ}\right)$ and $\mathrm{SiO}_{2}$ component peaks of the $\mathrm{Si}$ $2 \mathrm{p}$ core level profile could be observed throughout all experimental stages. This allowed the extent of $\mathrm{SiO}_{2}$ to $\mathrm{MnSiO}_{3}$ conversion to be approximated by expressing the integrated area of the $\mathrm{MnSiO}_{3}$ component peak as a percentage of the $\mathrm{SiO}_{2}$ component peak area. The $\mathrm{SiO}_{2}$ surfaces were prepared using a standard degreasing procedure of successive dips in acetone, methanol and isopropyl alcohol before being loaded into a UHV deposition and analysis system. Samples were then degassed at $\sim 200^{\circ} \mathrm{C}$ for $2 \mathrm{hs}$, with the UHV chamber reaching a maximum pressure of $5 \times 10^{-9}$ mbar during degassing. The XPS analysis was carried out using a VG Microtech electron spectrometer at a base pressure of $1 \times 10^{-9}$ mbar. The photoelectrons were excited with a conventional $\mathrm{Mg} \mathrm{K} \alpha(\mathrm{h} \nu=1253.6 \mathrm{eV}) \mathrm{x}$-ray source and an electron energy analyzer operating at a $20 \mathrm{eV}$ pass energy, yielding an overall resolution of $1.2 \mathrm{eV}$. High temperature annealing studies were carried out in vacuum at a pressure of $5 \times 10^{-9}$ mbar, with samples kept at the target temperature for 60 mins. Hydrochloric acid etched Mn chips, with a purity of $\sim 99.9 \%$, were used as a source material for the deposition of oxygen free metallic Mn thin films using electron beam evaporation. Metallic manganese thin film deposition was performed at elevated substrate temperature $\left(150^{\circ} \mathrm{C}\right)$ using an Oxford Applied Research EGC04 mini electron-beam evaporator, at a chamber pressure of $5 \times 10^{-9} \mathrm{mbar}$. The deposition of both partially and fully oxidized Mn films was carried out by the controlled introduction of $\mathrm{O}_{2}$ gas into the UHV chamber during metallic Mn deposition. The XPS core level spectra were curve fitted using Voigt profiles composed of Gaussian and Lorentzian line shapes in a 3:1 ratio and using a Shirley-type background. The full width at half maximum (FWHM) of the $\mathrm{Si} 2 \mathrm{p}$ bulk peak was $0.9 \mathrm{eV}$, with $\mathrm{SiO}_{2}$ and $\mathrm{Mn}$ silicate component peaks in the range 1.1 to $1.2 \mathrm{eV}$. The FWHM of the $\mathrm{O} 1 \mathrm{~s} \mathrm{SiO}_{2}$ component was $1.2 \mathrm{eV}$ with $\mathrm{Mn}$ silicate and Mn oxide peaks in the range of 1.2 to $1.1 \mathrm{eV}$.

It should be noted that curve fitting of the Mn $2 p$ spectrum could not be performed given that XPS ghost peaks ${ }^{8}$ emanating from the Mn $2 \mathrm{p}^{1 / 2}$ are present within the peak profile of the $\mathrm{Mn} 2 \mathrm{p}^{3 / 2}$ component. As such, only non-curve fitted Mn 2p spectra are included in this study. The Mn 2p spectra are primarily used to identify the presence of metallic
$\mathrm{Mn}$ and oxidized Mn species on the sample surface as these component peaks are easily identified from the $\mathrm{Mn} 2 \mathrm{p}^{3 / 2}$ peak profile without curve fitting. However, Mn $2 p$ spectra could not be used to conclusively identify the presence of differing oxidized Mn species such as Mn silicate and Mn oxide, therefore these chemical species are identified in this study using curve fitted $\mathrm{O} 1 \mathrm{~s}$ and $\mathrm{Si} 2 \mathrm{p}$ spectra.

High resolution transmission electron microscopy (HRTEM) studies were performed using a JEOL-JEM $3000 \mathrm{~F}$ and JEOL-JEM 4000EX electron microscopes operating at 300 and $400 \mathrm{kV}$, respectively. Samples in cross section geometry were prepared by the conventional method of grinding and polishing followed by $\mathrm{Ar}^{+}$milling in a Gatan PIPS until electron transparent. The HRTEM micrographs were calibrated using the silicon (111) planes spacing as a reference.

\section{EXPERIMENTAL RESULTS AND DISCUSSION}

Curve fitted $\mathrm{O} 1 \mathrm{~s}$ and $\mathrm{Si} 2 \mathrm{p}$ core level spectra taken from the $5.4 \mathrm{~nm}$ thermal $\mathrm{SiO}_{2}$ surface are shown in Fig. 1. The corresponding spectra taken following the deposition of $\mathrm{a} \sim 1 \mathrm{~nm}$ metallic $\mathrm{Mn}$ thin film onto the $\mathrm{SiO}_{2}$ surface at elevated substrate temperature $\left(150^{\circ} \mathrm{C}\right)$ are also shown in Fig. 1. Curve fitting analysis shows small changes to the core levels profiles suggesting that $\mathrm{Mn}$ deposition resulted in the growth of additional component peaks in both the $\mathrm{O} 1 \mathrm{~s}$ and Si $2 p$ spectra separated from the $\mathrm{SiO}_{2}$ components by 1.4 and $1.3 \mathrm{eV}$, respectively. These peaks are attributed to the presence of the $\mathrm{Mn}$ silicate species $\mathrm{MnSiO}_{3}$, in agreement with previous photoemission results. ${ }^{5} \mathrm{~A}$ series of high temperature vacuum anneals between $300^{\circ} \mathrm{C}$ and $500^{\circ} \mathrm{C}$ were then performed on the sample. The spectra in Fig. 1 show evidence for further Mn silicate formation following these anneals, and this is supported by changes in the Mn $2 \mathrm{p}$ spectrum in Fig. 2 which show the growth of an oxidized Mn component peak on the higher binding energy side of the

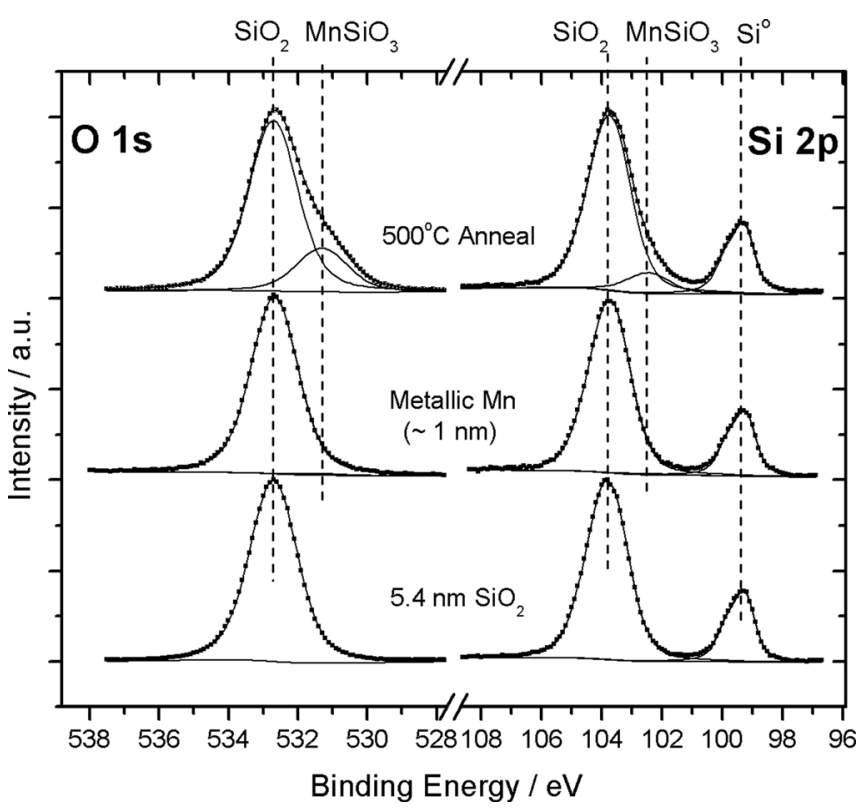

FIG. 1. Curve fitted O 1s and Si 2p spectra showing the growth of Mn silicate $\left(\mathrm{MnSiO}_{3}\right)$ following the deposition of metallic $\mathrm{Mn}(\sim 1 \mathrm{~nm})$ onto $\mathrm{SiO}_{2}$ thermal oxide surface and subsequent UHV annealing. 


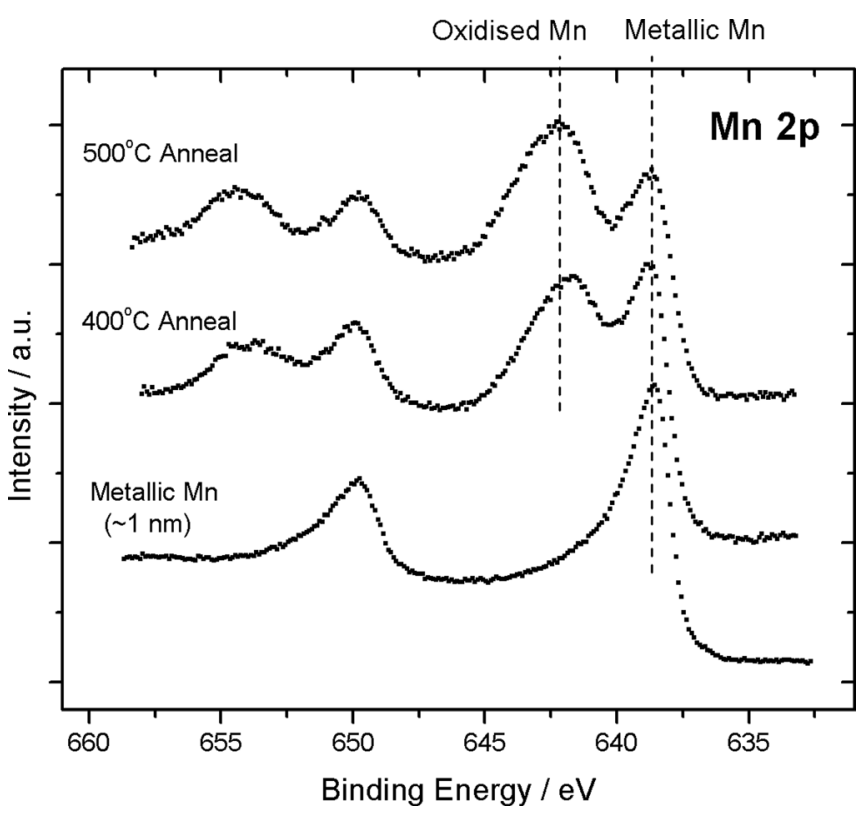

FIG. 2. Mn 2p spectra, corresponding to Fig. 1, show the presence of residual metallic Mn on the surface following $500^{\circ} \mathrm{C}$ annealing. This result suggests that the interaction of metallic $\mathrm{Mn}$ and $\mathrm{SiO}_{2}$ is self limiting at high temperature.

metallic Mn peak. ${ }^{9}$ The presence of residual metallic Mn following the $500^{\circ} \mathrm{C}$ anneal suggests that the interaction of metallic $\mathrm{Mn}$ with $\mathrm{SiO}_{2}$ is self limiting at this temperature, in agreement with previous results. ${ }^{5,7}$ Rudimentary peak fitting (not shown) of the Mn 2p spectra in Fig. 2 suggests that only $\sim 0.5 \mathrm{~nm}$ of the deposited $\mathrm{Mn}$ film was converted to Mn silicate following the $500^{\circ} \mathrm{C}$ anneal. This limited scale of $\mathrm{Mn}$ silicate growth can also be seen from the corresponding $\mathrm{Si}$ $2 p$ spectrum which shows that only $\sim 12 \%$ of the $\mathrm{SiO}_{2}$ component peak was converted to $\mathrm{Mn}$ silicate. The results shown in Figs. 1 and 2 suggest that the thickness of manganese silicate barrier layers formed through the deposition of purely metallic Mn is self limiting at high temperature. Based on photoemission thickness calculations ${ }^{10}$ the limiting thickness of the $\mathrm{MnSiO}_{3}$ was calculated to be approximately $2 \mathrm{~nm}$ following the $500^{\circ} \mathrm{C}$ vacuum anneal. It should be noted that while the $\mathrm{SiO}_{2}$ surfaces used in this study were degassed prior to Mn deposition at a temperature of $\sim 200^{\circ} \mathrm{C}$ for $2 \mathrm{hs}$, the work of Proost et al. ${ }^{11}$ suggests that this may not have been sufficient to remove all of the chemisorbed water present on the surface. As stated previously, Ablett et al. ${ }^{7}$ have suggested that the interaction of metallic Mn and absorbed water on silica surfaces may promote the growth of Mn oxide species, with these $\mathrm{Mn}$ oxide species subsequently reacting with $\mathrm{SiO}_{2}$ to form $\mathrm{Mn}$ silicate. Therefore, it is suggested that the presence of chemisorbed water may have contributed to the partial conversion of metallic Mn to Mn silicate seen in Figs. 1 and 2. However, this has not been shown conclusively in this study.

In order to determine if the chemical reactivity of metallic $\mathrm{Mn}$ on $\mathrm{SiO}_{2}$ surfaces is limited by the presence of additional oxygen species, specifically in the form of Mn oxide, a partially oxidized $\mathrm{Mn}$ film was deposited onto the $\mathrm{SiO}_{2}$ surfaces and annealed to high temperature. Figure 3 shows

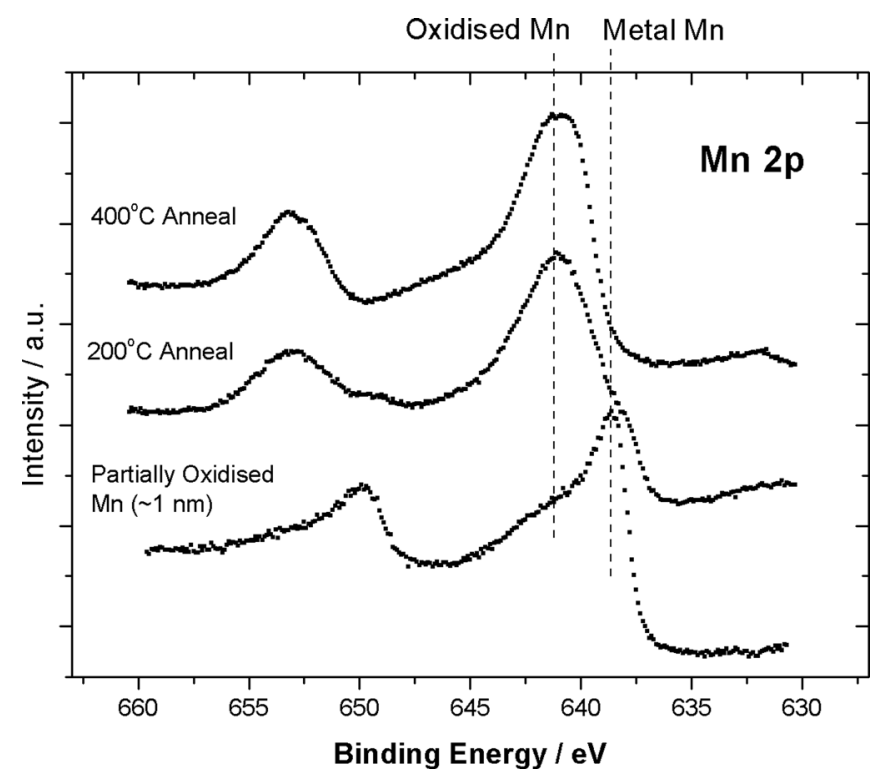

FIG. 3. Mn 2p spectra taken following the deposition of partially oxidized $\mathrm{Mn}(\sim 1 \mathrm{~nm})$ onto $\mathrm{SiO}_{2}$ show the presence of both metallic $\mathrm{Mn}$ and oxidized Mn component peaks. Spectra taken following $400^{\circ} \mathrm{C}$ annealing show the complete conversion of metallic Mn to Mn silicate.

Mn 2p spectra taken following the deposition of metallic Mn in an $\mathrm{O}_{2}$ partial pressure of $5 \times 10^{-8}$ mbar onto the $\mathrm{SiO}_{2}$ surface at elevated substrate temperature $\left(150^{\circ} \mathrm{C}\right)$, leading to an $\mathrm{O}_{2}$ exposure of $\sim 30$ Langmuir (L). The $\mathrm{Mn} 2 \mathrm{p}$ spectrum clearly shows the presence of both metallic Mn and oxidized Mn spectral components, with curve fitting analysis suggesting a metallic Mn:oxidized Mn ratio of 5:1. Angular resolved Mn $2 p$ spectra (not shown) indicate no evidence for spatial segregation between the oxidized and metallic species, which suggests that the oxygen content is homogenously distributed throughout the deposited film. While detailed chemical analysis of Mn species cannot be achieved by curve fitting the Mn $2 p$ spectrum as mentioned previously, the curve fitted O 1s and Si 2p spectra in Fig. 4 can be used to determine the chemical species present on the $\mathrm{SiO}_{2}$ surface following deposition of the partially oxidized $\mathrm{Mn}$ film. It can be seen from Fig. 4 that $\mathrm{O}$ 1s spectra show the presence of two additional component peaks on the lower binding energy (LBE) side of the $\mathrm{SiO}_{2}$ component following deposition. The peak at $531.3 \mathrm{eV}$ is again attributed to the presence of $\mathrm{Mn}$ silicate which formed upon deposition, which is confirmed by the growth of a Mn silicate component peak in the corresponding Si 2p spectrum at $102.6 \mathrm{eV}$ (Fig. 4). In addition to this, the $\mathrm{O} 1 \mathrm{~s}$ spectrum also shows evidence for a third component peak at a binding energy position of $530.0 \mathrm{eV}$, which is attributed to the presence of $\mathrm{Mn}$ oxide in agreement with previous studies. ${ }^{12}$ The formation of Mn oxide species following $\sim 30 \mathrm{~L} \mathrm{O}_{2}$ exposure is in agreement with the work of Lescop $^{13}$ who has shown that the oxidation of Mn can occur at oxygen exposure levels less than $20 \mathrm{~L}$. Based on this analysis, it is apparent that the chemical species present on the surface prior to high temperature annealing are metallic Mn, $\mathrm{Mn}$ oxide, $\mathrm{Mn}$ silicate, and $\mathrm{SiO}_{2}$. The sample was subsequently annealed to a maximum temperature of $400{ }^{\circ} \mathrm{C}$ in UHV and the corresponding photoemission spectra are also 


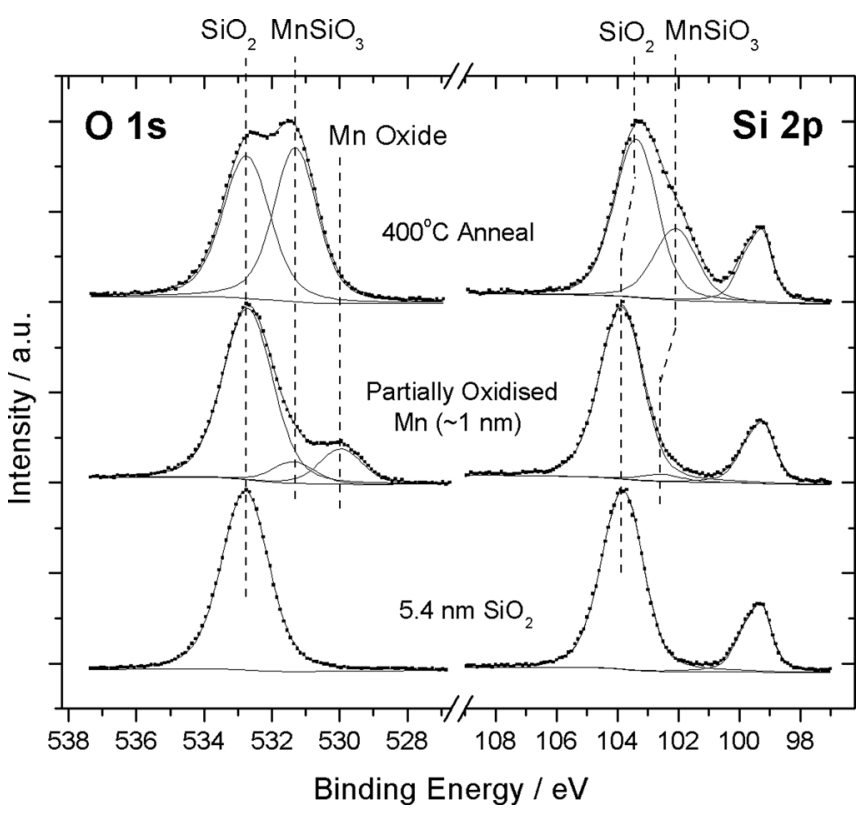

FIG. 4. Curve fitted O 1s and Si 2p spectra corresponding to Fig. 3. Spectra show the complete conversion of both metallic Mn and Mn oxide to form $\mathrm{MnSiO}_{3}$, resulting in higher levels of silicate growth than that seen in Fig. 1 which indicates the increased reactivity of partially oxidized Mn films on $\mathrm{SiO}_{2}$.

shown in Figs. 3 and 4 . It can be seen from Fig. 4 that annealing to $400{ }^{\circ} \mathrm{C}$ has resulted in considerable growth of Mn silicate, as evidenced by growth of the $\mathrm{MnSiO}_{3}$ component peaks in both the $\mathrm{O} 1 \mathrm{~s}$ and $\mathrm{Si} 2 \mathrm{p}$ spectra. Curve fitting of the Si 2 p spectrum following annealing suggests that $48 \%$ of the $\mathrm{SiO}_{2}$ component peak was converted to Mn silicate, which is a considerably larger value than that seen following the deposition of metallic Mn in Fig. 1. XPS thickness calculations ${ }^{10}$ suggest that the thickness of this silicate layer is $\sim 3 \mathrm{~nm}$. It is suggested that this increased thickness may be attributed to an increase in the chemical reactivity of the partially oxidized $\mathrm{Mn}$ species on $\mathrm{SiO}_{2}$, compared to that of the purely metallic Mn film. This increased chemical reactivity of the partially oxidized Mn film is also shown by the Mn 2p spectra in Fig. 3 which show no evidence for the presence of residual metallic $\mathrm{Mn}$ following $400{ }^{\circ} \mathrm{C}$ annealing, again in contrast to the results seen following the deposition of metallic Mn in Fig. 2.

Figure 5 shows HRTEM images taken from the $5.4 \mathrm{~nm}$ thermal $\mathrm{SiO}_{2}$ surface [Fig. 5(a)], as well as images taken following the growth of barrier layers using partially oxidized Mn [Fig. 5(b)] and metallic Mn [Fig. 5(c)]. The images are used to more accurately quantify the thickness of the barriers layers formed on both samples, and as such offer further evidence for the increased chemical reactivity of partially oxidized Mn. The HRTEM measured thickness values in Table I indicate that the thickness of the barrier layer formed using purely metallic Mn is $1.7 \mathrm{~nm}$ [Fig. 5(c)], while the Mn silicate layer formed using partially oxidized $\mathrm{Mn}$ is measured to be $2.6 \mathrm{~nm}$ [Fig. 5(b)]. It should be noted that the TEM thickness values shown in Table I are in close agreement with the corresponding values calculated using XPS, suggesting the photoemission calculations used in this study are accurate. It should also be noted that XPS thickness calcula-

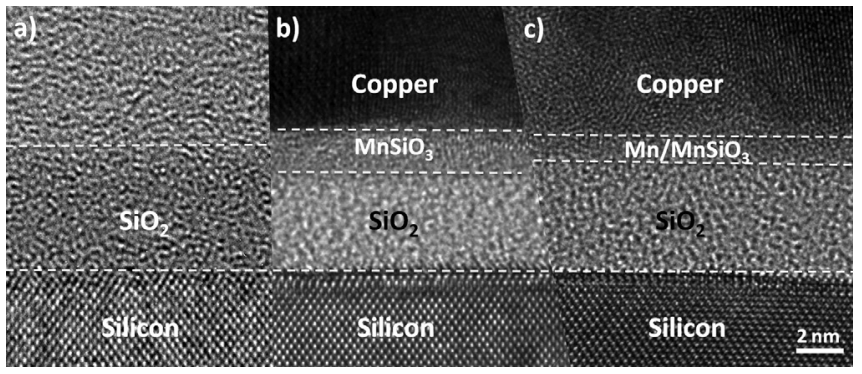

FIG. 5. HRTEM images taken from the as grown $\mathrm{SiO}_{2}$ thermal oxide (a), the barrier layer formed using partially oxidized $\mathrm{Mn}$ (b), and the barrier layer formed using metallic Mn (c). Images clearly show that the $\mathrm{MnSiO}_{3}$ layer formed using partially oxidized $\mathrm{Mn}$ is considerably thicker than that formed using metallic Mn. It can also be seen that $\mathrm{MnSiO}_{3}$ growth has resulted in a corresponding reduction in $\mathrm{SiO}_{2}$ thickness, indicating the conversion of $\mathrm{SiO}_{2}$ to $\mathrm{MnSiO}_{3}$ during barrier layer formation.

tions suggest that the deposited thickness of Mn in both films was the same $(\sim 1 \mathrm{~nm})$. Therefore, the increased thickness of the Mn silicate layer shown in Fig. 5(b) is attributed to an increase in the chemical reactivity of the partially oxidized Mn film compared to that of the purely metallic Mn film.

It should also be noted that while the partially oxidized Mn film consisted of $\sim 15 \%$ oxidized $\mathrm{Mn}$, the remaining oxygen required to form the fully oxidized $\mathrm{MnSiO}_{3}$ layer must come from the conversion of $\mathrm{SiO}_{2}$ to $\mathrm{Mn}$ silicate, given that all experimental stages were carried out in UHV. The conversion of $\mathrm{SiO}_{2}$ to $\mathrm{MnSiO}_{3}$ during barrier layer growth is confirmed by the HRTEM images in Fig. 5 which clearly show that the increased barrier layer thickness seen in Fig. 5(b) results in a corresponding reduction in the thickness of the underlying $\mathrm{SiO}_{2}$. This observation is analogous to a comparable study by Copel et al. ${ }^{14}$ who investigated the interaction of $\mathrm{La}_{2} \mathrm{O}_{3}$ films on $\mathrm{SiO}_{2}$ surfaces and reported that the growth of La silicate through thermal annealing resulted in a corresponding reduction in $\mathrm{SiO}_{2}$ thickness. The reduction of $\mathrm{SiO}_{2}$ thickness during the conversion of $\mathrm{SiO}_{2}$ to $\mathrm{MnSiO}_{3}$ is quantified in Table I, with TEM thickness values suggesting that the presence of $\mathrm{Mn}$ oxide species within the partially oxidized film allowed for increased levels of $\mathrm{SiO}_{2}$ conversion. Therefore, it is suggested that the presence of Mn oxide allows Mn silicate layers of increased thickness to be formed by facilitating the conversion of both $\mathrm{SiO}_{2}$ and $\mathrm{Mn}$ to $\mathrm{MnSiO}_{3}$. Based on these results it can be stated that the presence of additional oxygen within a metallic Mn film is essential in order to form $\mathrm{Mn}$ silicate films with a thickness greater than $\sim 2 \mathrm{~nm}$ on thermally grown $\mathrm{SiO}_{2}$.

It should be noted that the shift to LBE seen in the $\mathrm{SiO}_{2}$ component of the Si 2p spectra in Fig. 4 is attributed to the thinning of the $\mathrm{SiO}_{2}$ layer following $\mathrm{Mn}$ silicate growth. It

TABLE I. HRTEM thickness values corresponding to the images shown in Fig. 5.

\begin{tabular}{lcc}
\hline \hline & $\begin{array}{c}\mathrm{SiO}_{2} \\
\text { thickness (nm) }\end{array}$ & $\begin{array}{c}\text { Mn barrier layer } \\
\text { thickness (nm) }\end{array}$ \\
\hline Thermally grown $\mathrm{SiO}_{2}$ (5a) & 5.4 & - \\
Partially oxidized Mn (5b) & 4.1 & 2.6 \\
Metallic Mn (5c) & 4.5 & 1.7 \\
\hline \hline
\end{tabular}


has been shown by Iwata et al. ${ }^{15}$ that the binding energy (BE) separation between the $\mathrm{Si}^{\circ}$ and $\mathrm{SiO}_{2}$ components of the Si $2 p$ profile may be increased as a function of increasing $\mathrm{SiO}_{2}$ thickness, due to the buildup of surface electronic charge during the photoemission process. In agreement with this, curve fitting techniques suggest that the $\mathrm{Si}^{\circ}-\mathrm{SiO}_{2} \mathrm{BE}$ separation is reduced from an initial value of $4.4 \mathrm{eV}$ for the $5.4 \mathrm{~nm} \mathrm{SiO}_{2}$ surface to a value of $4.0 \mathrm{eV}$ following the growth of Mn silicate and corresponding reduction in $\mathrm{SiO}_{2}$ thickness. The affects of surface charging are accommodated for during the peak fitting process by linking the B.E. position of the Mn silicate component to that of the $\mathrm{SiO}_{2}$ component, using a $\mathrm{BE}$ separation of $1.4 \mathrm{eV}$ in agreement with previous studies. ${ }^{5}$

Along with the conversion of metallic Mn, the $\mathrm{O} 1 \mathrm{~s}$ spectra in Fig. 4 also show evidence for the complete conversion of Mn oxide to Mn silicate following high temperature annealing. This result indicates that $\mathrm{MnSiO}_{3}$ layers free from metallic $\mathrm{Mn}$ and Mn oxide can be formed by the thermal annealing of partially oxidized $\mathrm{Mn}$ on $\mathrm{SiO}_{2}$ surfaces. The conversion of Mn oxide to Mn silicate is in contrast to the finding of Gordon et $a l .{ }^{1,3}$ who have suggested that $\mathrm{Mn}$ oxide is unreactive on $\mathrm{SiO}_{2}$ surfaces. However, the chemical reactivity of Mn oxide species within a metallic Mn matrix may be different to that of fully oxidized Mn oxide films. Therefore, a metal free Mn oxide layer, with a thickness of $\sim 1 \mathrm{~nm}$, was deposited in order to determine the chemical stability of fully oxidized $\mathrm{Mn}$ on $\mathrm{SiO}_{2}$. The fully oxidized $\mathrm{Mn}$ film was formed by evaporation of metallic $\mathrm{Mn}$ in an $\mathrm{O}_{2}$ oxygen background pressure of $1 \times 10^{-7} \mathrm{mbar}$ at elevated substrate temperature of $150^{\circ} \mathrm{C}$. A post deposition anneal at the same temperature and $\mathrm{O}_{2}$ background pressure was then performed leading to a total $\mathrm{O}_{2}$ exposure of $\sim 400 \mathrm{~L}$. The Mn $2 \mathrm{p}$ spectrum taken following post-deposition annealing (not shown) displays no evidence for the presence of metallic $\mathrm{Mn}$ on the surface, showing that the film is fully oxidized. The corresponding $\mathrm{O} 1 \mathrm{~s}$ spectrum in Fig. 6 shows the presence of a Mn oxide component at a binding energy position of $530.2 \mathrm{eV}$, which is close to that previously attributed to the Mn oxide species $\mathrm{MnO} .{ }^{12}$ Given the difficulty in curve fitting Mn $2 p$ spectra obtained using conventional non-monochromated XPS, the exact stoichiometry of the Mn oxide species deposited in this study cannot be established. However, it can be clearly stated that the film is fully oxidized and free from metallic Mn.

A series of high temperature vacuum anneals between $300^{\circ} \mathrm{C}$ and $500{ }^{\circ} \mathrm{C}$ were then performed on the sample. In agreement with the results of the partially oxidized Mn film, it can be seen from both the $\mathrm{O}$ 1s and Si 2p spectra in Fig. 6 that high temperature annealing results in the conversion of $\mathrm{Mn}$ oxide to $\mathrm{Mn}$ silicate. Given that there is no evidence for the presence of metallic Mn on the surface of this sample, this experimental result shows that fully oxidized $\mathrm{Mn}$ can also be converted to $\mathrm{Mn}$ silicate following high temperature annealing on $\mathrm{SiO}_{2}$ surfaces. This result is in agreement with recent publications ${ }^{16,17}$ which have reported that $\mathrm{Mn}$ oxide layers formed on $\mathrm{SiO}_{2}$ surface using chemical vapor deposition can be converted to $\mathrm{Mn}$ silicate following thermal annealing. In addition to this, it has also been shown that other metal oxide species such as $\mathrm{La}_{2} \mathrm{O}_{3}{ }^{14}$ and $\mathrm{MgO}_{\mathrm{x}}{ }^{18}$ can be converted to

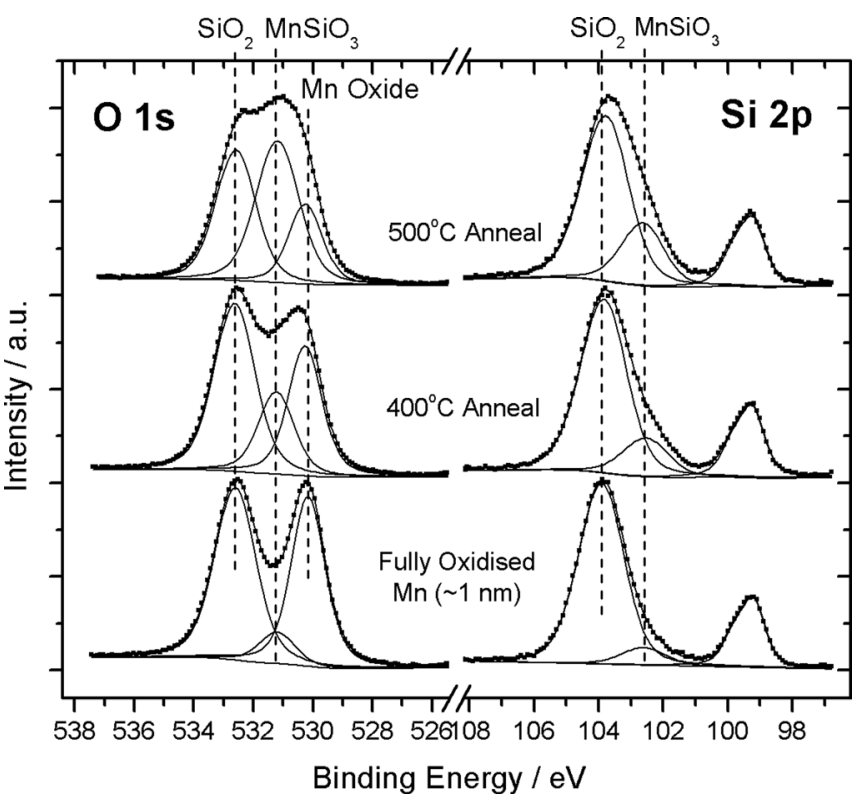

FIG. 6. Curve fitted O 1s and Si 2p spectra taken following the deposition of a fully oxidized Mn oxide layer $(\sim 1 \mathrm{~nm})$ and subsequent UHV annealing, showing the conversion of Mn oxide to Mn silicate. Spectra taken from the $5.4 \mathrm{~nm} \mathrm{SiO} 2$ surface prior to $\mathrm{Mn}$ oxide deposition are not shown, but are identical to those shown in Figs. 1 and 4.

metal silicate species following thermal annealing on $\mathrm{SiO}_{2}$ surfaces. The scale of $\mathrm{Mn}$ silicate growth is again quantified using curve fitting techniques, with the Si 2p spectra in Fig. 6 showing that $36 \%$ of the $\mathrm{SiO}_{2}$ component peak being converted to $\mathrm{Mn}$ silicate. It should be noted that the $\mathrm{SiO}_{2}$ component of the Si 2p spectrum in Fig. 6 does not show the same shift to LBE previously observed in Fig. 4 following the reduction of $\mathrm{SiO}_{2}$ thickness, and the corresponding reduction of surface electronic charging effects. It is suggested that these charging effects were not reduced to the same extent in Fig. 6, given that lower of levels of $\mathrm{SiO}_{2}$ conversion to $\mathrm{MnSiO}_{3}$ were observed in this sample. Also, the presence of Mn oxide species, with comparatively high resistivity, on the $\mathrm{SiO}_{2}$ surface in Fig. 6 may have also increased the level of photoemission surface charging affects compared to that seen in Fig. 4.

Further experiments (not shown) involving the deposition of partially oxidized Mn films of greater thickness ( $>1.5$ $\mathrm{nm}$ ) were also carried out in order to determine if the deposited film thickness is also a limiting factor in Mn silicate growth. Spectra taken after $500^{\circ} \mathrm{C}$ annealing showed evidence for greater levels of Mn silicate growth than that seen in Figs. 3 and 4, however, there was also evidence for the presence of residual metallic Mn which had not been converted to Mn silicate at this temperature. Therefore, based on the results of this study it is suggested that even when sufficient levels of Mn oxide are present on the surface the thickness of $\mathrm{Mn}$ silicate layers formed on $\mathrm{SiO}_{2}$ is still self limiting at high temperature.

\section{CONCLUSIONS}

The results of this study show that the growth of Mn silicate barrier layers on $\mathrm{SiO}_{2}$ surfaces is self limited by the 
availability of additional oxygen, beyond that which is present within the $\mathrm{SiO}_{2}$ layer. It has been shown that $\mathrm{a} \sim 1 \mathrm{~nm}$ metallic Mn film cannot be fully converted to Mn silicate following $500{ }^{\circ} \mathrm{C}$ annealing. As a result, Mn silicate layers with a thickness greater than $1.7 \mathrm{~nm}$ cannot be formed following the deposition of purely metallic $\mathrm{Mn}$ and subsequent UHV annealing on a thermally grown $\mathrm{SiO}_{2}$ layer. It has also been shown that a partially oxidized $\mathrm{Mn}$ film of similar thickness $(\sim 1 \mathrm{~nm})$, containing approximately $15 \% \mathrm{Mn}$ oxide, can be fully converted to form a Mn silicate layer of greater thickness $(2.6 \mathrm{~nm})$ which is free from metallic Mn and Mn oxide. HRTEM images taken from these samples show that $\mathrm{MnSiO}_{3}$ growth causes a corresponding reduction in the $\mathrm{SiO}_{2}$ layer thickness. This result is attributed to the conversion of $\mathrm{SiO}_{2}$ to $\mathrm{Mn}$ silicate during UHV annealing and suggests that while the presence of $\mathrm{Mn}$ oxide is required to achieve full conversion of $1 \mathrm{~nm}$ Mn films to Mn silicate, the remaining oxygen required for silicate growth can be obtained from the $\mathrm{SiO}_{2}$ film. Therefore, only low levels of additional oxygen are required to increase film reactivity. This may be of relevance for the practical implementation of $\mathrm{MnSiO}_{3}$ barrier layer formation processes in device fabrication, given that the integration of excess oxygen into the Mn layer may decrease the reportedly high diffusivity of metallic $\mathrm{Mn}$ within $\mathrm{Cu}$ layers, ${ }^{7}$ one of the main factors which has led to the investigation of $\mathrm{Mn}$ based barriers layers for $\mathrm{Cu}$ interconnects. It has also been shown in this study that fully oxidized Mn films, free from metallic Mn, can be converted to Mn silicate using thermal annealing on $\mathrm{SiO}_{2}$ surfaces. Given that conformal deposition techniques such as atomic layer deposition are more suited to the deposition of metal oxide species than contaminant free metallic films, the use of fully or partially oxidized $\mathrm{Mn}$ films may offer a route to integrate Mn silicate structures into ultrathin barrier layer formation. However, it should be noted that the chemical reactivity of
Mn oxide films on $\mathrm{SiO}_{2}$ may depend greatly on factors such as oxide stoichiometry and film deposition method.

\section{ACKNOWLEDGMENTS}

The authors would like to gratefully acknowledge financial support from the SFI PI program under Grant No. 08/ IN.1/I2052. J.G. Lozano would like to acknowledge the support of the European Commission under the Marie Curie Programme 2009. The authors would also like to thank the Tyndall National Institute in Cork, Ireland for $\mathrm{SiO}_{2}$ thermal oxide fabrication.

${ }^{1}$ R. Gordon, H. Kim, International Patent No. WO 2009/117670 A2, 24 Sept. (2009).

${ }^{2}$ Y. Lee and Y.-L. Kuo, JOM 59, 44 (2007).

${ }^{3}$ Y. Au, Y. Lin, H. Kim, E. Beh, Y. Liu, and R. G. Gordon, J. Electrochem. Soc. 157, D 341 (2010).

${ }^{4}$ J. Koike and M. Wada, Appl. Phys. Lett. 87, 041911 (2005).

${ }^{5}$ P. Casey, J. Bogan, B. Brennan, and G. Hughes, Appl. Phys. Lett. 98, 113508 (2011).

${ }^{6}$ J. Iijima, Y. Fujii, K. Neishi, and J. Koike, J. Vac. Sci. Technol. B 27, 1963 (2009).

${ }^{7}$ J. M. Ablett, J. C. Woicik, Z. Tokei, S. List, and E. Dimasi, Appl. Phys. Lett. 94, 042112 (2009).

${ }^{8}$ M. O. Krause and J. G. Ferreira, J. Phys. B: At. Mol. Phys. 8, 12 (1975).

${ }^{9}$ U. Manju, D. Topwal, G. Rossi, and I. Vobornik, Phys. Rev. B 82, 035442 (2010).

${ }^{10}$ M. P. Seah and S. J. Spencer, Surf. Interface Anal. 33, 640 (2002).

${ }^{11}$ J. Proost, E. Kondoh, G. Vereecke, M. Heyns, and K. Maex, J. Vac. Sci. Technol., B 16, 2091 (1998).

${ }^{12}$ A. A. Audi and P. M. A. Sherwood, Surf. Interface Anal. 33, 274 (2002).

${ }^{13}$ B. Lescop, Appl. Surf. Sci. 252, 2276 (2006).

${ }^{14}$ M. Copel, E. Cartier, and F. M. Ross, Appl. Phys. Lett. 78, 1607 (2001).

${ }^{15}$ S. Iwata and A. Ishizaka, J. Appl. Phys. 79, 6653 (1996).

${ }^{16}$ N. M. Phuong, K. Matsumoto, K. Maekawa, and J. Koike, Abstracts of Papers, Materials Research Society Spring Meeting, San Francisco Abstract O6.4 (2011).

${ }^{17}$ V. K. Dixit, K. Neishi, N. Akao, and J. Koike, IEEE Trans. Device Mater. Reliab. 11, 295 (2011).

${ }^{18}$ P. Casey and G. Hughes, J. Appl. Phys. 107, 074107 (2010). 